University of Nebraska - Lincoln

DigitalCommons@University of Nebraska - Lincoln

Faculty Publications: Department of

Entomology

Entomology, Department of

1998

\title{
Susceptibility of House Fly (Diptera: Muscidae) Larvae to Entomopathogenic Nematodes (Rhabditida: Heterorhabditidae, Steinernematidae
}

\author{
David B. Taylor \\ University of Nebraska-Lincoln, dave.taylor@ars.usda.gov \\ Allen L. Szalanski \\ University of Nebraska-Lincoln \\ Byron J. Adams \\ University of Nebraska-Lincoln, byron_adams@byu.edu \\ Richard D. Peterson II \\ University of Nebraska-Lincoln, padr20@yahoo.com
}

Follow this and additional works at: https://digitalcommons.unl.edu/entomologyfacpub

Part of the Entomology Commons

Taylor, David B.; Szalanski, Allen L.; Adams, Byron J.; and Peterson, Richard D. II, "Susceptibility of House Fly (Diptera: Muscidae) Larvae to Entomopathogenic Nematodes (Rhabditida: Heterorhabditidae, Steinernematidae" (1998). Faculty Publications: Department of Entomology. 205.

https://digitalcommons.unl.edu/entomologyfacpub/205

This Article is brought to you for free and open access by the Entomology, Department of at DigitalCommons@University of Nebraska - Lincoln. It has been accepted for inclusion in Faculty Publications: Department of Entomology by an authorized administrator of DigitalCommons@University of Nebraska - Lincoln. 


\title{
Susceptibility of House Fly (Diptera: Muscidae) Larvae to Entomopathogenic Nematodes (Rhabditida: Heterorhabditidae, Steinernematidae)
}

\author{
DAVID B. TAYLOR, ALLEN L. SZALANSKI, ${ }^{1}$ BYRON J. ADAMS, ${ }^{1}$ AND RICHARD D. PETERSON II
}

Midwest Livestock Insects Research Laboratory, USDA-ARS, Department of Entomology, University of Nebraska, Lincoln, NE 68583

\begin{abstract}
Environ. Entomol, 27(6): 1514-1519 (1998)
ABSTRACT The potential for entomopathogenic nematodes to control flies in cattle feedlots was determined by screening 40 strains representing 8 species of Heterorhabditis Poinar and 5 species of Steinernema Travassos for virulence toward 3rd-instar house flies (maggots), Musca domestica L. None of the 22 strains of Heterorhabditis infecting maggots caused significant levels of mortality in a filter paper assay. Ten strains of Steinernema infected maggots, of which 7 strains (4 S. carpocapsae (Weiser), 2 S. feltiae (Filipjev), and 1 S. scapterisci Nguyen \& Smart) caused significant mortality. Ten Heterorhabditis strains and 10 Steinernema strains successfully reproduced for $\geq 2$ generations in maggots. No difference was observed between 72 -h survival of maggots and adult emergence. Six strains of Steinernema were selected for 10 generations on maggots and then compared with unselected lines. No difference in pathogenicity between selected and unselected lines was observed. Two strains of S. feltiae, SN and UNK-36, and 2 of the best Heterorhabditis strains, $H$. bacteriophora Poinar OSWEGO and H. megidis Poinar, Jackson \& Klein HF-85 were tested in a fresh bovine manure substrate. All 4 strains produced significant fly mortality in the manure substrate, although the $S$. feltiae strains had significantly lower $\mathbf{L C}_{50}$ values than did the Heterorhabditis spp. The most promising strain, $S$. feltiae $\mathrm{SN}$, gave $\mathrm{LC}_{50}$ and $\mathrm{LC}_{99}$ values of 4 and 82 infective juveniles per maggot, respectively. These doses were equivalent to 2.7 and 55 infective juveniles per gram of manure and 5.1 and 104 infective juveniles per square centimeter of surface area. Infective juveniles capable of infecting greater wax moth larvae, Galleria mellonella (L), survived in manure for up to 10 wk without hosts.
\end{abstract}

KEY WORDS Musca domestica, biological control, feedlot, entomopathogenic nematodes

NEMATODEs OF THE genera Heterorhabditis Poinar and Steinemema Travassos, in conjunction with their symbiotic bacteria, Photorhabdus spp. and Xenorhabdus spp., are pathogenic to many insect pests (Poinar 1979) and are effective biological control agents for soil associated insects (Klein 1990). Several studies have addressed the efficacy of entomopathogenic nematodes against the house fly, Musca domestica $\mathrm{L}$, in the laboratory and confined poultry environment (Renn et al. 1985; Geden et al. 1986; Belton et al. 1987; Mullens et al. 1987a, b). Although moderate levels of mortality were observed in petri dish-filter paper assays, virulence was greatly reduced when house fly larvae (maggots) were exposed in chicken manure substrates. Georgis et al. (1987) demonstrated that poultry manure was toxic to infective nematode larvae.

The filth fly breeding substrate in the cattle feedlot environment differs significantly from that of the confined poultry environment. Nitrogenous wastes are

This article reports the results of research only. Mention of a proprietary product does not constitute an endorsement or a recommendation by USDA for its use.

${ }^{1}$ Department of Plant Pathology, University of Nebraska, Lincoln, NE 68583 excreted by cattle as water soluble urea, whereas they are in the form of uric acid in poultry manure. Also, the manure pit of a poultry house would tend to be relatively free of plant material and soil. Manure in feedlots is frequently mixed with soil, grain, and haylage. These differences may make the filth fly substrate in the cattle feedlot environment more hospitable to entomopathogenic nematodes than that in confined poultry systems. Despite these differences, the efficacy of entomopathogenic nematodes for the control of flies in the confined cattle environment has not been explored (Petersen 1993). In addition, few of the available species and strains of nematodes have been screened against filth flies, and conflicting results have been obtained for some of the nematode species, possibly because of differences in strain pathogenicity (Laumond et al. 1979, Gaugler 1988).

The potential for entomopathogenic nematodes to control filth flies in cattle feedlots was determined by screening 40 strains representing 8 species of Heterorhabditis and 5 species of Steinemema for pathogenicity toward maggots. Strains that successfully reproduced in maggots were reared for 10 generations on maggots in an effort to increase pathogenicity toward this host. Finally, the most promising strains were 
evaluated for pathogenicity and persistence in bovine manure.

\section{Materials and Methods}

Nematode and Fly Cultures. Species, strains, and sources of nematodes used are presented in Table 1. Classification of nematode strains to species follows that of Poinar (1990). Nematodes were reared using late-instar greater wax moths, Galleria mellonella (L.), obtained from Grubco (Hamilton, $\mathrm{OH}$ ) using methods similar to Dutky et al. (1964). Nematodes were harvested with White traps (White 1927), quantified by counting the number of nematodes in five, 5- $\mu$ l samples and using the average to dilute to solutions to the needed concentration, and stored in tissue culture flasks at $15^{\circ} \mathrm{C}$.

House flies were from a 9-yr-old colony collected from a feedlot in the vicinity of Lincoln, NE. Fly larvae were reared on a wheat bran diet at $25^{\circ} \mathrm{C}$. Third instars were obtained for all experiments by removing them from the medium after $3 \mathrm{~d}$ of development.

Susceptibility of Maggots on Filter Paper. The virulence of Heterorhabditis spp. and Steinernema spp. toward maggots was tested using a filter paper assay. Fifteen 3rd instars were placed in a 9-cm petri dish lined with a filter paper disk ( $7 \mathrm{~cm}$ diameter). One milliliter of nematode-water suspension $(\approx 100$ nematodes per maggot) was applied to the filter paper. Water was used for control replicates. Maggot mortality was recorded at $3 \mathrm{~d}$ and adult fly emergence was scored at $2 \mathrm{wk}$. Reproductive success of the nematodes was evaluated by placing cadavers in White traps $7 \mathrm{~d}$ after infection. White traps were maintained at $25^{\circ} \mathrm{C}$ and checked daily for the emergence of infective juvenile nematodes. Nematodes were collected from the White traps and stored in tissue culture flasks at $15^{\circ} \mathrm{C}$. Nematodes remained viable for $>1$ yr under these conditions, but cultures for bioassays were all $<1$ mo old.

Selection. Strains that successfully reproduced in maggots were maintained on that host for as many generations as possible. General procedures were the same as outlined in the susceptibility test except 25 maggots were used in each petri dish. Infections were attempted 3 times per generation. If, after 3 attempts, the nematodes failed to reproduce, that strain was dropped from the selection study. After selection for 10 generations, selected lines were compared with lines of the same strain maintained in greater wax moth larvae. The concentrations of nematodes used for this comparison were 500,125 , and 15 nematodes per maggot. Otherwise, procedures were the same as for the susceptibility study. To reduce any effect that parental host might have on pathogenicity, progeny of the original comparisons were tested for 2 additional generations giving comparisons of $F_{10}$ with $F_{0}, F_{11}$ with $F_{1}$, and $F_{12}$ with $F_{2}$ selected lines.

Manure Substrate. Two strains of Steinernema feltiae (Filipjev), H. bacteriophora OSWEGO, and $\boldsymbol{H}$. megidis HF-85, were tested for pathogenicity toward maggots in fresh bovine manure. Manure ( $<48 \mathrm{~h}$ old) was collected from the ground. Manure was placed in a pan and mixed until uniform. Samples of manure ( $150 \mathrm{~g}$ wet weight) were partitioned into plastic containers (11 cm diameter, $8 \mathrm{~cm}$ deep) with screened holes ( $7.5 \mathrm{~cm}$ diameter) in the lid. Two replicates of 100 three-d-old maggots per strain were inoculated with $15,500,7,500,3,500,1,500,700$, or 300 nematodes per container. The different nematode densities were run in successive weeks. The 2 Heterorhabditis spp. were tested at the highest 2 doses, S. feltiae UNK-36 was tested at the highest 4 doses and $S$. feltiae $\mathrm{SN}$ was tested at all 6 doses. Two weeks after initiation, house fly adults were counted in each container. Persistence of nematodes in the manure substrate was examined by placing 5 greater wax moth larvae in each container for $48 \mathrm{~h}$ each $\mathrm{wk}$ beginning $3 \mathrm{wk}$ after initiation for the 15,500 and 7,500 tests. After $48 \mathrm{~h}$, wax moth larvae were removed to $9-\mathrm{cm}$ petri dishes lined with a piece of moistened filter paper ( $7 \mathrm{~cm}$ diameter) and scored for mortality $2 \mathrm{~d}$ later. Dead wax moth larvae were observed for nematode infections. Wax moth larvae from which no nematodes emerged were dissected to check for the presence of nematodes. Water was added to the manure containers once per week to maintain their original weight.

Data Analysis. Filter paper assays were conducted for 3 successive weeks with 3 replications of each nematode strain per week for a total 9 replicates of 15 maggots each per strain. A 1-way analysis of variance (ANOVA) with a complete block design (PROC GLM, SAS Institute, 1985) was used to analyze maggot mortality and adult emergence. Mortality data are presented as percentage mortality, although actual mortality was used for statistical tests. A $t$-test was used to separate the means, and Dunnett $t$-test (PROC GLM, SAS Institute 1985) was used to compare treatments with controls.

Probit analysis (PROC PROBIT, SAS Institute 1985) was used to calculate $\mathrm{LC}_{50}$ values for the selection and manure tests using a natural log transformation of the nematode concentrations. Overlap of the $95 \%$ fiducial limits was used to determine significance (Fuxa 1987).

\section{Results}

Seven Steinernema strains-S. feltiae SN and UNK36, S. carpocapsae UNK-34, Kapow, Mex-1 and Mex-2, and S. scapterisci-produced significant mortality of maggots in the filter paper assay (Table $1, F=20.37$; df $=42,326 ; P<=0.001$ ). An additional 3 strains of Steinernema and 22 strains of Heterorhabditis produced low levels of infection, but mortality did not differ significantly from the control. Five Steinernema and 5 Heterorhabditis strains failed to infect maggots. Maggot survival and adult emergence did not differ significantly $(F=1.99 ; \mathrm{df}=1,78 ; P=0.162)$. Very few of the maggots alive after $3 \mathrm{~d}$ failed to pupate and emerge as adults. Dissections of unemerged pupae revealed no nematodes. Control mortalities were $0 \%$ for the 3-d maggot count and averaged $3 \%$ for the adult emergence count. Inspection of cadavers for several weeks following infection revealed successful repro- 
Table 1. Species and strains of Heterorhabditis spp. and Steinemema spp. evaluated for virulence to house fly larvae

\begin{tabular}{|c|c|c|c|c|c|c|}
\hline Species & Strain & Origin & Source & $\begin{array}{l}\% \text { mortality } \pm S D \\
\text { at } 72 \mathrm{~h}\end{array}$ & Group & Reproduced \\
\hline \multicolumn{7}{|l|}{ A. Heterorhabditis spp. } \\
\hline H. argentinensis Stock & RAF & Rafaela, Argentina & Stock $^{a}$ & $5.2 \pm 5.5$ & D & - \\
\hline H. argentinensis Stock & $\mathrm{JJ}$ & Rabuela, Argentina & Jackson $^{b}$ & $0.0 \pm 0.0$ & D & - \\
\hline H. bacteriophora Poinar & NC-1 & North Carolina & Brooks $^{e}$ & $0.7 \pm 2.2$ & D & + \\
\hline H. bacteriophora Poinar & $\mathrm{OH}-25$ & Oregon & $\operatorname{Liu}^{d}$ & $1.5 \pm 2.9$ & $\mathrm{D}$ & + \\
\hline H. bacteriophora Poinar & $\mathrm{OH}-23$ & Oregon & Liu $^{d}$ & $3.7 \pm 5.9$ & $\mathrm{D}$ & + \\
\hline H. bacteriophora Poinar & lewiston & North Carolina & Jackson $^{b}$ & $0.7 \pm 2.2$ & D & + \\
\hline H. bacteriophora Poinar & & Brecon, Australia & Akhurst" & $0.0 \pm 0.0$ & D & - \\
\hline H. bacteriophora Poinar & AB Road & Nebraska & Adams ${ }^{f}$ & $2.9 \pm 4.9$ & D & + \\
\hline H. bacteriophora Poinar & A cows & Nebraska & Adams $f$ & $2.2 \pm 3.3$ & $\mathrm{D}$ & + \\
\hline H. bacteriophora Poinar & OSWEGO & North Carolina & Jackson $^{b}$ & $4.4 \pm 5.8$ & D & + \\
\hline H. bacteriophora Poinar & Riwaka & New Zealand & Bumell/Joyces & $4.5 \pm 2.9$ & D & - \\
\hline H. bacteriophora Poinar & HP88 & Utah & Westerman $^{h}$ & $0.0 \pm 0.0$ & D & - \\
\hline H. howaiiensis Gardner, Stock \& Kaya & MG3 prime & Hawaii & Stock ${ }^{a}$ & $1.5 \pm 2.9$ & D & - \\
\hline H. hepialus Stock, Strong \& Gardner & - & California & Stock $^{a}$ & $5.2 \pm 6.5$ & D & - \\
\hline$H_{\text {, indicus Poinar, Karunakar \& Hastings }}$ & - & Coimbatore, India & Burnell/Joyces & $0.0 \pm 0.0$ & $\mathrm{D}$ & - \\
\hline H. marelatus Liu \& Berry & OH-10 & Oregon & $\mathrm{Liu}^{d}$ & $5.9 \pm 7.0$ & $\bar{D}$ & - \\
\hline H. megidis Poinar, Jackson \& Klein & HO-1 & Ohio & Akhurste & $4.4 \pm 3.3$ & $\mathrm{D}$ & - \\
\hline H. megidis Poinar, Jackson \& Klein & $\mathbf{Y}$ & Netherlands & Smits $^{i}$ & $0.7 \pm 2.2$ & $\mathrm{D}$ & - \\
\hline H. megidis Poinar, Jackson \& Klein & HF- 85 & Netherlands & Westerman $^{h}$ & $3.7 \pm 8.9$ & $\mathrm{D}$ & + \\
\hline H. megidis Poinar, Jackson \& Klein & NLH94.1 & Netherlands & Smits ${ }^{i}$ & $4.5 \pm 5.8$ & $\mathrm{D}$ & + \\
\hline H. megidis Poinar, Jackson \& Klein & $\mathbf{x}$ & British Columbia, Canada & Smits' & $1.5 \pm 2.9$ & D & - \\
\hline H. megidis Poinar, Jackson \& Klein & NLHE87.3 & Netherlands & Smits & $2.9 \pm 4.9$ & D & - \\
\hline H. megidis Poinar, Jackson \& Klein & Sp-Y & Europe & Smits ${ }^{t}$ & $0.7 \pm 2.2$ & D & - \\
\hline H. zealandica Poinar & NZH & New Zealand & Akhurst ${ }^{e}$ & $4.4 \pm 3.3$ & D & + \\
\hline H. sp. & OH-31 & Oregon & Liu $^{d}$ & $0.0 \pm 0.0$ & D & - \\
\hline$H$. sp. & K122 & Ireland & Griffin's & $2.9 \pm 4.9$ & D & - \\
\hline$H$. sp. & $\mathrm{OH}-1$ & Oregon & $\mathrm{Liu}^{d}$ & $2.2 \pm 3.3$ & D & - \\
\hline \multicolumn{7}{|l|}{ B. Steinernema spp. } \\
\hline S. carpocapsae (Weiser) & UNK-34 & South Dakota & Jackson $^{b}$ & $42.9 \pm 27.9$ & $\mathbf{A B}$ & + \\
\hline S. carpocapsae (Weiser) & Mex-1 & Mexico & Jackson $^{b}$ & $15.5 \pm 17.3$ & C & + \\
\hline S. carpocapsae (Weiser) & Mex-2 & Mexico & Jackson ${ }^{b}$ & $17.8 \pm 4.7$ & C & + \\
\hline S. carpocapsae (Weiser) & Agriotos & Aeriobo, Spain & Jackson & $1.5 \pm 2.9$ & $\mathbf{D}$ & + \\
\hline S. carpocapsae (Weiser) & Kapow & Kapow, Poland & Jackson $^{b}$ & $36.3 \pm 28.3$ & B & + \\
\hline S. carpocapsae (Weiser) & UK & United Kingdom & Jackson $^{b}$ & $5.2 \pm 6.5$ & D & + \\
\hline S. feltiae (Filipjev) & UNK-36 & South Dakota & Jackson $^{b}$ & $49.6 \pm 25.4$ & $\mathbf{A}$ & + \\
\hline S. feltiae (Filipjev) & SN & France & Jackson ${ }^{b}$ & $50.4 \pm 13.8$ & $\mathbf{A}$ & + \\
\hline S. glaseri (Steiner) & - & - & Jackson $^{b}$ & $0.0 \pm 0.0$ & D & - \\
\hline S. riobravis Cabanillas, Poinar \& Raulston & - & Texas & Cabanillas $^{*}$ & $0.0 \pm 0.0$ & D & - \\
\hline S. scopterisci Nguyen \& Smart & - & - & Jackson $^{b}$ & $35.5 \pm 27.5$ & B & + \\
\hline S. sp. & ARP blowout & Nebraska & Adams ${ }^{f}$ & $0.0 \pm 0.0$ & D & + \\
\hline S. sp. & ARAP YS7 & Nebraska & Adams ${ }^{f}$ & $0.0 \pm 0.0$ & D & - \\
\hline C. Control & - & - & - & $0.0 \pm 0.0$ & D & - \\
\hline
\end{tabular}

Data are the mean percentage of house fly larvae killed in filter paper assays. Each species was replicated 9 times with 15 house fly larvae per replicate. Groupings are based upon $t$-tests using least significant difference.

a Stock, S. P., University La Plata CTR Parasities and Vectors Studies, La Plata, Argentina.

b Jackson, J. J., Northern Grain Insects Research Laboratory, USDA-ARS, Brookings, SD.

$\boldsymbol{c}$ Brooks, M. A., Department of Entomology, University of Minnesota, St. Paul, MN.

${ }^{d}$ Liu, J., Department of Entomology, Oregon State University, Corvallis, OR.

- Akhurst, R. J., CSIRO Division of Entomology, GPO Box 1700 Canberra, ACT 2601 Australia.

${ }^{\text {B.J.A. }}$.

\& Burnell, A. M., and S. A. Joyce, Department of Biology, St. Patricks College, Maynooth, Kildare, Ireland.

${ }^{h}$ Westerman, P. R., Agrar. Hogeschool Friesland, P.O. Box 15288901 BV Leeuwarden, Netherlands.

' Smits, P. H. Research Institute Plant Protection, DLO, POB 9060, Wageningen NL-6700 GW, Netherlands.

${ }^{f}$ Griffin, C. T., Department of Biology, St. Patricks College, Maynooth, Kildare, Ireland.

${ }^{\boldsymbol{k}}$ Cabanillas, H. E. Crop Insects Research Laboratory, Subtropical Agriculture Research Laboratory, USDA-ARS, Weslaco, TX.

duction and new infective juveniles for 20 nematode strains-10 Steinemema and 10 Heterorhabditis (Table 1).

Six strains of Steinernema reproduced for 10 generations in maggots (Table 2). Comparison of selected and unselected lines indicated that the selection procedure had no effect on the virulence of the nematodes toward house fly. $\mathrm{LC}_{50}$ values for S. feltiae ranged from 10 to 18 infective nematodes per host, whereas those for S. carpocapsae and S. scapterisci ranged between 38 and 55 infective nematodes per host.

Two strains of S. feltiae and 2 Heterorhabditis species (Table 3) were evaluated for their virulence toward maggots in manure. Each caused a reduction in the number of house fly adults emerging, although $\mathbf{L C}_{50}$ values for the Heterorhabditis species were higher than those for S. feltiae. The LC $\mathrm{L}_{50}$ for S. feltiae UNK-36 in manure ( 30 infective juveniles per maggot) did not differ from that observed in the filter paper assay. 
Table 2. Pathogenicity of seleeted and unselected Steinemema strains toward house fly larvae

\begin{tabular}{|c|c|c|c|c|c|c|c|}
\hline Species & Strain & Selected & No. hosts & Slope \pm SE & $\mathrm{LC}_{50}{ }^{a}$ & $95 \% \mathrm{CL}$ & $x^{2}$ \\
\hline \multirow[t]{2}{*}{ S. feltiae } & UNK-36 & - & 389 & $0.64 \pm 0.07$ & 18 & $13-24$ & 95.16 \\
\hline & & + & 401 & $0.68 \pm 0.07$ & 14 & $10-19$ & 83.35 \\
\hline \multirow[t]{2}{*}{ S. feltiae } & SN & - & 397 & $0.60 \pm 0.07$ & 10 & $6-14$ & 65.51 \\
\hline & & + & 391 & $0.85 \pm 0.11$ & 11 & $8-15$ & 52.53 \\
\hline \multirow[t]{2}{*}{ S. carpocapsae } & UNK-34 & - & 404 & $0.59 \pm 0.06$ & 30 & $22-39$ & 111.49 \\
\hline & & + & 396 & $0.62 \pm 0.06$ & 28 & $21-36$ & 113.30 \\
\hline \multirow[t]{2}{*}{ S. carpocapsae } & Mex & - & 391 & $0.51 \pm 0.10$ & 55 & $44-69$ & 26.06 \\
\hline & & + & 403 & $0.69 \pm 0.07$ & 40 & $31-50$ & 138.88 \\
\hline \multirow[t]{2}{*}{ S. carpocapsae } & Kapow & - & 400 & $0.57 \pm 0.05$ & 47 & $37-58$ & 156.32 \\
\hline & & + & 402 & $0.84 \pm 0.07$ & 33 & $26-40$ & 143.54 \\
\hline \multirow{2}{*}{ S. scapterisci } & & - & 399 & $0.53 \pm 0.05$ & 43 & $31-56$ & 107.50 \\
\hline & & + & 394 & $0.65 \pm 0.06$ & 37 & $28-47$ & 132.50 \\
\hline
\end{tabular}

${ }^{a}$ Number of nematodes per host.

However, the $\mathrm{LC}_{50}$ for S. feltiae $\mathrm{SN}$ in manure (4 infective juveniles per maggot) was about one-half the value observed on filter paper. $\mathrm{LC}_{99}$ and $\mathrm{LC}_{98}$ values for $S$. feltiae $\mathrm{SN}$ were 82 and 58 nematodes per host or 104 and 74 nematodes per square centimeter of manure surface area, respectively.

Survival of infective stage larval nematodes in manure was examined by placing 5 greater wax moth larvae in cups inoculated with 15,500 or 7,500 and 100 maggots beginning $3 \mathrm{wk}$ after inoculation. No hosts were available for nematode reproduction after the initial 100 maggots. Infective juveniles of the Heterorhabditis bacteriophora and S. feltiae persisted for 10 wk (Table 4). Mortality of the wax moth larvae varied greatly, even within treatments. Therefore, the mortality data were not subjected to statistical analysis.

\section{Discussion}

Evaluation of 40 strains of entomopathogenic Heterorhabditis and Steinernema nematodes revealed 7 strains of Steinernema spp. that produced significant levels of house fly mortality (Table 1). S. carpocapsae, S. feltiae, and S. scapterisci were the most promising; however, strains of $S$. carpocapsae varied greatly in their virulence. Of the 6 strains of S. carpocapsae eval- uated, 2 produced relatively high mortality, 2 moderate mortality, and 2 very low mortality. Both strains of S. feltiae were highly effective as was the 1 strain of $S$. scapterisci. None of the Heterorhabditis spp. showed promise for use in house fly control, although several strains successfully reproduced.

No differences were observed between maggot survival and adult emergence. This facilitated the later tests to evaluate house fly susceptibility to nematodes in manure substrates. Isolating maggots from these media can be tedious. Adult emergence gave us a more efficient method to measure nematode induced mortality.

Care must be used when comparing these results with those of previous studies at the species level because of changes in taxonomy. Steinernema feltiae of previous authors (Renn et al. 1985, Geden et al. 1986, Mullens et al. 1987a) were actually S. carpocapsae, whereas S. bibionis of those authors were S. feltiae (Poinar 1990). Among the Heterorhabditis spp., $\boldsymbol{H}$. heliothidis of Renn et al. (1985) were $H$. zealandica, and $H$. heliothidis of Geden et al. (1986) and Mullens et al. (1987a) were $H$. bacteriophora.

Steinemema feltiae was the most virulent species toward maggots followed by S. carpocapsae in the filter paper assay. This differs from that of Mullens et al.

Table 3. Number of adult house flies emerging from bovine manure substrate inoeulated with 100 house fly larvae and $155-3$ infective Heterorhabditis spp. or Steinernema feltiae per fly larva

\begin{tabular}{|c|c|c|c|c|c|c|c|c|c|c|}
\hline \multirow{2}{*}{ Species } & \multirow{2}{*}{ Strain } & \multicolumn{6}{|c|}{ No. infective nematodes per fly larva } & \multicolumn{3}{|c|}{ Probit analysis } \\
\hline & & $155^{a}$ & $75^{b}$ & $35^{c}$ & $15^{d}$ & $T^{\circ}$ & $3^{f}$ & $\overline{L C_{50}{ }^{8}}$ & $95 \% \mathrm{CL}$ & Slope \\
\hline H. bacteriophora & OSWEGO & $4.0 \pm 1.0^{*}$ & $60.5 \pm 0.5^{*}$ & & & & & 83 & $78-89$ & $1.754 \pm 0.583$ \\
\hline H. megidis & HF- 85 & $10.5 \pm 0.5^{*}$ & $81.0 \pm 1.0^{*}$ & & & & & 106 & $101-113$ & $2.127 \pm 0.770$ \\
\hline S. feltiae & UNK-36 & $0.0 \pm 0.0^{*}$ & $1.0 \pm 1.0^{*}$ & $51.5 \pm 2.5^{*}$ & $68.5 \pm 6.5$ & & & 30 & 5-63 & $1.372 \pm 0.450$ \\
\hline S. feltiae & SN & $0.0 \pm 0.0^{*}$ & $0.0 \pm 0.0^{*}$ & $20.0 \pm 3.4^{*}$ & $22.7 \pm 15.5^{*}$ & $33.5 \pm 2.5 *$ & $61.5 \pm 3.5^{*}$ & 4 & $3-5$ & $0.776 \pm 0.051$ \\
\hline Control & - & $75.5 \pm 12.5$ & $96.5 \pm 2.5$ & 89.5 & $\pm 3.5^{h}$ & 94.5 & $\pm 1.5^{i}$ & - & - & - \\
\hline
\end{tabular}

* Differs significantly at $P<0.05$ from control, Dunnett $t$-test.

a $F=33.4 ; \mathrm{df}=4,5 ; P=0.001$.

${ }^{b} F=1,192.7 ; \mathrm{df}=4,5 ; P<0.001$.

${ }^{e} \boldsymbol{F}=171.2 ; \mathrm{df}=2,3 ; \boldsymbol{P}=\mathbf{0 . 0 0 1}$.

${ }^{d} F=36.2 ; \mathrm{df}=2,3 ; P=0.008$.

- $F=169.5$; df $=1,2 ; P=0.006$.

$f_{F}=75.1 ; \mathrm{df}=1,2 ; P=0.013$.

E No. infective juvenile nematodes per host.

${ }^{\text {h }}$ One control was used for the 35 and 15 nematodes per maggot treatments.

One control was used for the 7 and 3 nematodes per maggot treatments. 
Table 4. Mean number of greater wax moth larvae dead after 48-h exposure to manure after initial inoculation with 100 house fly larvae and 155 or 75 Heterorhabditis spp. or S. feltiae per fly larva

\begin{tabular}{|c|c|c|c|c|c|c|c|c|c|}
\hline \multirow{2}{*}{ Species } & \multirow{2}{*}{ Strain } & \multicolumn{8}{|c|}{ Weeks after inoculation } \\
\hline & & 3 & 4 & 5 & 6 & 7 & 8 & 9 & 10 \\
\hline H. bacte & OSWEGO & $3.75 \pm 1.64^{a}$ & $1.50 \pm 1.12^{a}$ & $0.00 \pm 0.00$ & $1.50 \pm 1.50^{\circ}$ & $1.25 \pm 1.09^{a}$ & $1.25 \pm 1.30$ & $0.75 \pm 0.83$ & $1.00 \pm 1.00^{a}$ \\
\hline H. megidis & HF-85 & $3.50 \pm 1.66^{a}$ & $2.75 \pm 1.48^{a}$ & $0.25 \pm 0.43$ & $0.75 \pm 0.83$ & $1.25 \pm 1.09$ & $1.25 \pm 1.09$ & $0.50 \pm 0.87$ & $1.25 \pm 0.83$ \\
\hline S. feltiae & UNK-36 & $4.75 \pm 0.43^{a}$ & $3.50 \pm 1.12^{a}$ & $3.50 \pm 1.12^{a}$ & $2.50 \pm 1.50^{a}$ & $1.25 \pm 1.09^{n}$ & $1.00 \pm 0.00^{a}$ & $2.50 \pm 1.12^{a}$ & $1.75 \pm 1.09^{a}$ \\
\hline S. feltiae & SN & $4.50 \pm 0.87^{a}$ & $3.25 \pm 2.05^{a}$ & $2.50 \pm 2.50^{\circ}$ & $3.75 \pm 0.83^{a}$ & $2.25 \pm 2.28^{a}$ & $1.00 \pm 0.43^{a}$ & $1.50 \pm 1.12$ & $1.00 \pm 0.00$ \\
\hline Control & - & $0.25 \pm 0.43$ & $0.50 \pm 0.87$ & $0.50 \pm 0.87$ & $0.50 \pm 0.50$ & $0.25 \pm 0.43$ & $0.25 \pm 0.43$ & $0.25 \pm 0.43$ & $1.25 \pm 0.83$ \\
\hline
\end{tabular}

Five wax moth larvae per treatment.

Nematode presence confirmed in $\geq 1$ greater wax moth larva.

(1987a), who found S. carpocapsae (= S. feltiae Breton and $S$. feltiae Mexican) to be more virulent than $S$. feltiae (= S. bibionis $\mathrm{KL}$ and S. bibionis $\mathrm{SN})$. Both our study and that of Mullens et al. (1987) found Heterorhabditis spp. to have low virulence, whereas Geden et al. (1986) reported higher virulence for $H$. bacteriophora (=H. heliothidis) than S. carpocapsae $(=S$. feltiae DD-136) and S. glaseri. S. glaseri had very low virulence in both Geden et al. (1986) and our study. Of the 8 Heterorhabditis species we tested, only $2-H$ bacteriophora and $H$. zealandica - had been examined for virulence toward house flies in previous studies. Three of the 5 Steinernema species had been previously examined.

Serial passage through maggots for 10 generations did not change the pathogenicity of any of the Steinernema strains (Table 2). Although initially disappointing, these results indicate that nematode strains can be screened effectively for pathogenicity toward maggots, and possibly other hosts, without acclimation to that host for several generations. In addition, greater wax moth larvae can be used as hosts for en vivo mass production without reducing pathogenicity toward maggots.

Other studies have documented the pathogenicity of several strains of entomopathogenic nematodes toward house fly larvae in filter paper assays (Renn et al. 1985, Geden et al. 1986, Belton et al. 1987, Mullens et al. 1987a). However, all of those studies focused upon the use of these nematodes for the control of flies in chicken manure. The eventual failure of these programs was attributed to the nematodes inability to survive in chicken manure (Georgis et al. 1987). In contrast, we found that the nematodes not only survive and remain infective in manure for $>1 \mathrm{mo}$, but that their pathogenicity is equal to, or greater than, that observed in filter paper assays (Tables 2 and 3). Our results appear to differ from those of Shapiro et al. (1996), who found manure reduced nematode virulence when added to soil as a fertilizer. However, Shapiro et al. examined only S. carpocapsae, a species we did not test in the manure substrate because it did not perform as well as S. feltiae in the filter paper assays. Bednarek and Gaugler (1997) found S. feltiae populations actually increased with the addition of manure to soils supporting our results.

Our persistence studies (Table 4) were conducted in the absence of hosts for nematode reproduction. Presumably, in a feedlot environment, fresh hosts will be available for the nematodes to cycle continuously, thus not only extending the persistence of the nematodes, but possibly increasing the population with time. Based upon the $\mathbf{L C}_{99}$ value of 104 nematodes per square-centimeter of surface area, we project an application rate of 1 million nematodes per square-meter of feedlot. We estimate (unpublished data) that $\approx 10,000$ infective juvenile nematodes are produced per maggot. Hence, successful reproduction in 100 maggots per square-meter will maintain a nematode population adequate for $99 \%$ control. Skoda et al. (1996) estimated an average population of about 2,200 stable flies, Stomoxys calcitrans (L.), and 4,000 house flies or 6,200 flies total per square-meter throughout the feedlot. Therefore, only .1.5\% of the infected maggots would need to support complete nematode development to maintain a constant population at the LC $_{99}$ level.

\section{Acknowledgments}

We thank R. J. Akhurts, M. A. Brooks, A. M. Burnell, H. E. Cabanillas, C. T. Griffin, J. J. Jackson, S. A. Joyce, J. Liu, P. H. Smits, S. P. Stock, and P. R. Westerman for providing nematode stocks. K. Pruess and B. Siegfried (University of Nebraska) provided helpful suggestions and critical reviews of the manuscript. This work was done in cooperation with the Institute of Agriculture and Natural Resources, University of Nebraska, Lincoln, NE, and is published as Journal Series, Nebraska Agricultural Research Division Paper No. 11924.

\section{References Cited}

Bednarek, A. J., and R. Gaugler. 1997. Compatibility of soil amendments with entomopathogenic nematodes. J. Nematol. 29: 220-227.

Belton, P., T. A. Rutherford, D. B. Trotter, and J. M. Webster 1987. Heterorhabditis heliothidis: potential biological control agent of house flies in caged-layer poultry barns. J. Nematol. 19: 263-266.

Dutky, S. R., J. V. Thompson, and G. E. Cantwell. 1964. A technique for the mass propagation of the DD-136 nematode. J. Insect Pathol. 6: 417-422.

Fuxa, J. R. 1987. Spodoptera frugiperda susceptibility to nuclear polyhedrosis virus isolates with reference to insect migration. Environ. Entomol. 16: 218-223.

Gaugler, R. 1988. Ecological considerations in the biological control of soil-inhabiting insects with entomopathogenic nematodes. Agric. Ecosyst. Environ. 24: 351-360.

Geden, C. J., R. C. Axtell, and W. M. Brooks. 1986. Susceptibility of the house fly, Musca domestica (Diptera: Mus- 
cidae), to the entomogenous nematodes Steinernema feltiae, S. glaseri (Steinemematidae). J. Med. Entomol. 23: 326-332.

Georgis, R., B. A. Mullens, and J. A. Meyer. 1987. Survival and movement of insect parasitic nematodes in poultry manure and their infectivity against Musca domestica. J. Nematol. 19: 292-295.

Klein, M. G. 1990. Efficacy against soil-inhabiting insect pests, pp. 195-214. In R. Gaugler and H. K. Kaya [eds.], Entomopathogenic nematodes in biological control. CRC, Boca Raton, FL.

Laumond, D, H. Mauleon, and A. Kermarrec. 1979. Donnes nouvelles sur le spectre d'hotes et le parasitisme du nematode entomophage Neoplectana carpocapsae. Entomophaga 24: 113-127.

Mullens, B. A., J. A. Meyer, and T. L. Cyr. 1987a. Infectivity of insect-parasitic nematodes (Rhabditida: Steinemematidae, Heterorhabditidae) for larvae of some manurebreeding flies (Diptera: Muscidae) . Environ. Entomol. 16: 769-773.

Mullens, B. A., J. A. Meyer, and R. Georgis. 1987b. Field tests of insect-parasitic nematodes (Rhabditida: Steinernematidae, Heterorhabditidae) against larvae of manurebreeding flies (Diptera: Muscidae) on caged-layer poultry facilities. J. Econ. Entomol. 80: 438-442.

Petersen, J. J. 1993. Biotic agents to control house flies and stable flies, pp. 70-77. In G. D. Thomas and S. R. Skoda [eds.], Rural flies in the urban environment? North Central Regional Research Publication No. 335.

Poinar, G. O., Jr. 1979. Nematodes for biological control of insects. CRC, Boca Raton, FL.

1990. Taxonomy and biology of Steinernematidae and Heterorhabditidae, pp. 23-61. In R. Gaugler and H. K. Kaya [eds.], Entomopathogenic nematodes in biological control. CRC, Boca Raton, FL.

Renn, N., G. Barson, and P. N. Richardson. 1985. Preliminary laboratory tests with two species of entomophilic nematodes for control of Musca domestica in intensive animal units. Ann. Appl. Biol. 106: 229-233.

SAS Institute. 1985. Users manual, version 6.0. SAS Institute, Cary, NC.

Shapiro, D. I., G. L. Tylka, and L. C. Lewis. 1996. Effects of fertilizers on virulence of Steinernema carpocapsae. Appl. Soil Ecol. 3: 27-34.

Skoda, S. R., G. D. Thomas, and J. B. Campbell. 1996. Comparison of core sampling and pupal traps for monitoring immature stable flies and house flies (Diptera: Muscidae) in beef feedlot pens. J. Econ. Entomol. 89: 428-434.

White, G. F. 1927. A method for obtaining infective nematode larvae from cultures. Science (Wash. D.C.) 66: 302-303.

Recetved for publication 5 February 1998; accepted 6 July 1998. 